\title{
Long-Term Grey Matter Changes in First Episode Psychosis: A Systematic Review
}

\author{
Ruth Gallardo-Ruiz'1, Benedicto Crespo-Facorro ${ }^{2,3}$, \\ Esther Setién-Suero ${ }^{2,3} \otimes$, and Diana Tordesillas-Gutierrez ${ }^{1,3}$ \\ ${ }^{1}$ Neuroimaging Unit, Technological Facilities,Valdecilla Biomedical Research Institute IDIVAL, Santander, Cantabria, Spain \\ ${ }^{2}$ Marqués de Valdecilla University Hospital, Department of Psychiatry, School of Medicine, University of Cantabria, IDIVAL, Santander, Spain \\ ${ }^{3}$ CIBERSAM, Biomedical Research Network on Mental Health Area, Madrid, Spain
}

\begin{abstract}
Objective To determine possible progressive changes of the grey matter at the first stages of the schizophrenia spectrum disorders, and to determine what regions are involved in these changes.

Methods We searched the literature concerning studies on longitudinal changes in grey matter in first-episode psychosis using magnetic resonance imaging, especially studies with an interval between scans of more than a year. Only articles published before 2018 were searched. We selected 19 magnetic resonance imaging longitudinal studies that used different neuroimaging analysis techniques to study changes in cerebral grey matter in a group of patients with a first episode of psychosis.

Results Patients with first episode of psychosis showed a decrease over time in cortical grey matter compared with a group of control subjects in frontal, temporal (specifically in superior regions), parietal, and subcortical regions. In addition to the above, studies indicate that patients showed a grey matter decrease in cerebellum and lateral ventricles volume.

Conclusion The results suggest a decrease in grey matter in the years after the first episode of psychosis. Furthermore, the results of the studies showed consistency, regardless of the methods used in their analyses, as well as the time intervals between image collections
\end{abstract}

Psychiatry Investig 2019;16(5):336-345

Key Words Grey matter, First-episode psychosis, Schizophrenia, Magnetic resonance imaging, Longitudinal.

\section{INTRODUCTION}

The first-episode psychosis (FEP) is the first manifestation of the characteristic symptoms, such as hallucinations or delusions, of schizophrenia spectrum disorders (SSD). These disorders involve a strong element of social dysfunction and severe cognitive impairments. The causes of these disorders remain largely unknown, but evidence indicates that it arises from changes in the development of the central nervous system. ${ }^{1,2}$

Magnetic resonance imaging (MRI) is the most established and widely used approach for the investigation of human

Received: September 3, 2018 Revised: December 21, 2018

Accepted: February 10, 2019

$\triangle$ Correspondence: Esther Setién Suero, M.Sc, PhD

Marqués de Valdecilla University Hospital, Department of Psychiatry, School of Medicine, University of Cantabria, IDIVAL, Avenida Cardenal Herrera Oria s/n, 39011, Santander, Spain

Tel: +34-942-203826, E-mail: setiensuero@hotmail.com

(a) This is an Open Access article distributed under the terms of the Creative Commons Attribution Non-Commercial License (https://creativecommons.org/licenses/by$\mathrm{nc} / 4.0$ ) which permits unrestricted non-commercial use, distribution, and reproduction in any medium, provided the original work is properly cited. brain structure in vivo. ${ }^{3,4}$ Different studies have shown that MRI is a technique with great potential in mental health research. Specifically, neuroimaging studies in FEP have shown neuroanatomical abnormalities, and they have observed reduced volume of grey matter (GM) and altered white matter (WM) integrity during the early stages of SSD., Furthermore, abnormalities in GM have been replicated in different longitudinal studies. ${ }^{7-9}$ Moreover, longitudinal clinical studies in patients with SSD have observed an increase in functional deterioration during the first years of follow-up after the onset of the disease. ${ }^{10}$ This deterioration could be associated with the aforementioned cerebral structural changes. Therefore, we consider it appropriate and relevant to review studies of changes in brain morphology during the first years of evolution of the disease. In addition, this review will take into account studies that used different methodologies, such as Voxel-based morphometry (VBM), ${ }^{3,11}$ Regions of interest (ROI) manual, automated or semi-automated technique, ${ }^{12}$ and Cortical Pattern Matching (CPM) technique. ${ }^{13}$ This way, a global view of the bibliography in longitudinal MRI studies is given. 
Our main goals with this systematic review are to determine possible progressive changes of the GM at the first stages of the disease, after a FEP, and to determine what regions are involved in these changes.

\section{MATERIAL AND METHODS}

In this review, we have included studies with a longitudinal analysis of GM in patients with FEP, compared with a group of healthy controls using MRI.

\section{Data sources}

A systematic review of the literature was carried out in compliance with the Preferred Reporting Items for Systematic Review and Meta-Analysis (PRISMA), ${ }^{14}$ and through a search of scientific journals on PubMed. We have selected English-language articles published between the years 2003 and 2018. Specifically, MRI studies with a longitudinal design that had a relationship between GM volume and FEP, compared with control group.

The following categories were used for the search. First search (1): grey matter, first episode psychosis, neuroimaging, longitudinal. Second search (2): grey matter, first episode psychosis, neuroimaging, follow-up studies. Third search (3): (grey matter) AND (longitudinal OR progressive OR follow-up) AND (first episode psychosis OR schizophrenia) AND mri.

At the same time, we performed a search on the OVID MEDLINE database, and we did not find any articles related to the search criteria.

The selection in the PubMed database was conducted by two researchers (a physicist and a psychologist). We found 321 studies; of them, 34 repeated articles were excluded. From these 287 articles, 269 were excluded after reading the abstracts and/or the results. Next, 3 articles were excluded because they did not identify the relationship between decrease in GM over time and FEP using MRI, or include affective psychosis in the FEP groups. We considered that there were articles that reported a decrease of GM in FEP as such, 4 articles were included manually. A total of 19 articles were included in the systematic review (Figure 1).

\section{Database study selection}

We have only included studies with samples of patients with diagnosis of FEP. We did not take into account schizoaffective, schizotypal, schizophreniform, depression, or bipolar disorder. Studies that included drugs effects on illness course have been excluded. Other studies that investigated childhood-onset schizophrenia, articles without longitudinal design or interval between scans equal to or less than one year, reviews, meta-analyses, and case studies, were also excluded.

\section{Data extraction}

The following data were extracted from the selected studies: Author, year of publication of the study, number of subjects, age of the patients at first scan, interval between the MRI scan (years/ on average), covariates; analyzed regions, image analysis method, and longitudinal findings (Tables 1,2, and 3).

Regarding the Tesla value of the MRI scanner, all of the MR images have been acquired with a 1.5-T scanner.

It is important to mention that the authors of the selected articles use different terms for First Episode Psychosis (FEP), including First Episode Schizophrenia (FES and FESZ). For heuristic reasons, we always use a single term, FEP.

This review focused on the relationship between FEP and progressive GM volume change. It was not our objective to research the relationship between this change and different treatments, clinical outcomes, cognitive and functional performance, or scores on different tests.

\section{RESULTS}

After reading methods and results, 19 articles were chosen. MRI longitudinal studies used VBM, ROI, and CPM techniques, to analyze the cerebral cortical GM and changes over time in a group of patients with FEP in comparison with a group of control subjects (Table 4).

\section{Voxel based morphometry}

Various automated techniques have been developed in recent years, notably VBM. VBM is an automated technique used to search for possible differences in anatomic brain structure between groups, and most commonly, to examine GM. However, it can also be used to identify differences in the brain tissue types (e.g., grey matter, white matter, etc), density, and volume of brain matter, and it is possible to measure the entire brain.

Four articles included the longitudinal image analysis using VBM. In the study by Farrow et al., ${ }^{15}$ they observed that 2 years after the first scan, patients with FEP showed decreased volumes of GM in the frontal cortex [right posterio-lateral frontal cortex-Broadmann Area (BA) 44, bilateral medial frontal gyrus/bilateral anterior cingulate gyrus-BA 11/32, bilateral pre-central gyrus-BA 6/4], temporal cortex (left inferior/middle temporal gyrus-BA 20/21), parietal cortex (left post-central gyrus), and right cerebellum. Likewise, a study published by Whitford et al. ${ }^{16}$ details that the FEP group showed GM loss over 2.5 years of follow-up interval in the parietal and temporal lobes bilaterally. Mane et al. ${ }^{17}$ found decreases in GM in FEP, compared with healthy individuals in the left superior temporal gyrus (STG), and right orbitofrontal gyrus between 1-4 year after first scan. They found that FEP patients showed 
an increase in bilateral lingual gyrus and right cuneus.

In the longitudinal study by Asami et al., ${ }^{18}$ the results presented a progressive GM reduction in the frontal, temporal, and parietal lobes in FEP 1.5 year after the first scan. These regions included temporal regions [bilateral STG including Heschl gyrus (HG)], frontal regions (bilateral superior, middle and inferior frontal gyrus), orbifrontal cortex and precentral gyrus, parietal regions (bilateral postcentral gyrus and supramarginal gyrus), limbic regions (bilateral insula), anterior cingulate gyrus (ACG) (bilateral rostral and dorsal subregions and left subgenual subregion), posterior cingulate gyrus (PGC), and right cerebellum.

\section{Region of interest}

ROI analysis method is used in 14 studies, and all of them, except for the study by DeLisi and Hoff ${ }^{19}$ showed a progres- sive decrease in GM volume in different regions over time in FEP patients.

ROI analysis in neuroimaging refers to selecting a specific area or brain region. This method can be used to extract those regions associated to a specific neurological disorder. This technique can be performed using automated or manual tracing of the different brain areas. But manually tracing ROI is time consuming, hard for a large sample study, and there is a lack of reproducibility in different laboratories.

Although ROI analysis is relatively accurate, developments in automated anatomical labeling offer individual anatomical images with a minimum of manual intervention.

\section{ROI automated}

In this review, we found a single study that uses automated ROI. DeLisi and Hoff ${ }^{19}$ reported that there were no significant

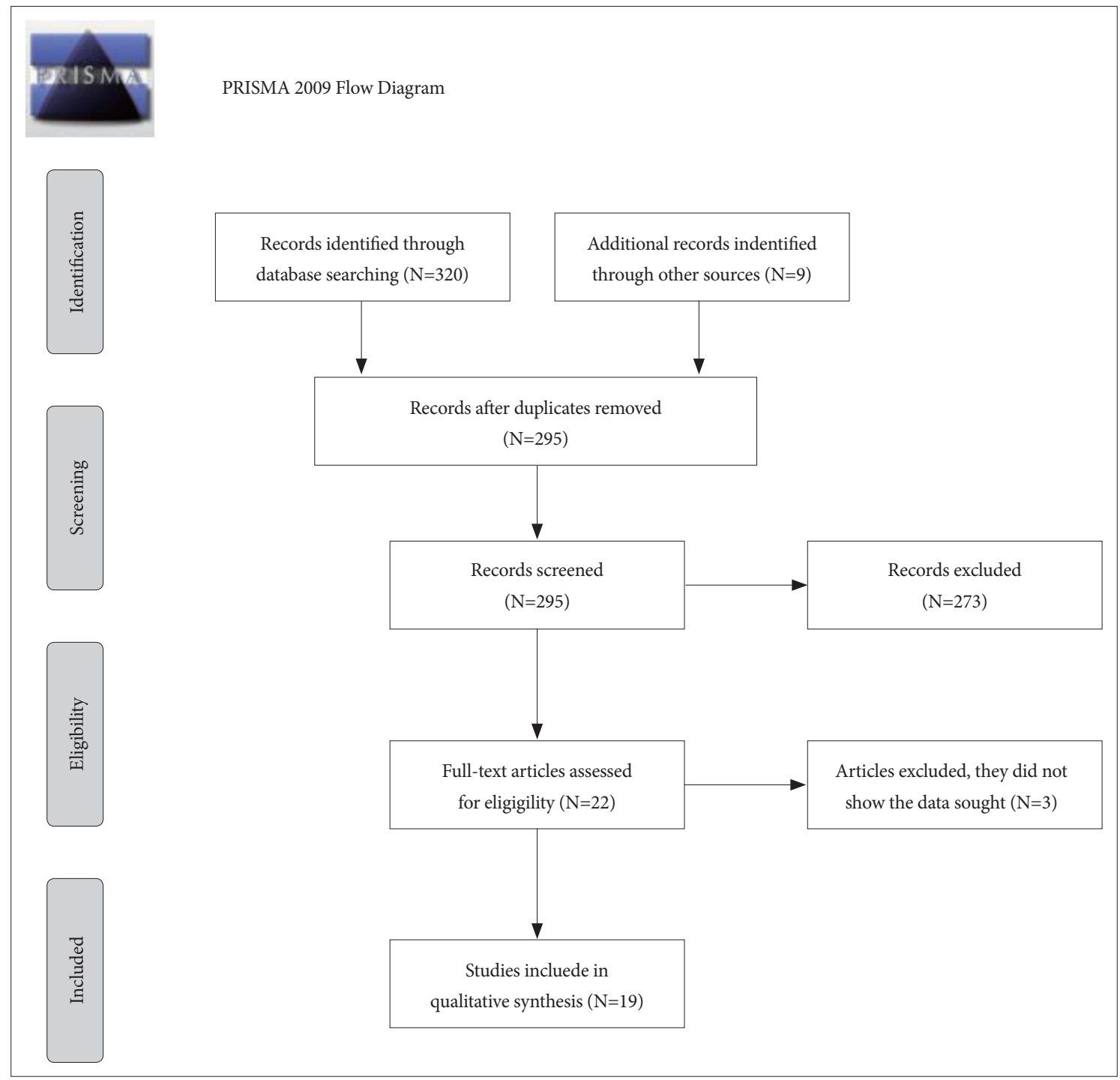

Figure 1. Flow diagram. 
Table 1. Voxel-based morphometry/cortical pattern matching

\begin{tabular}{|c|c|c|c|c|c|c|c|}
\hline $\begin{array}{c}\text { Authors/ } \\
\text { year }\end{array}$ & Country & Sample & $\begin{array}{l}\text { Age first } \\
\text { scan }\end{array}$ & $\begin{array}{l}\text { Num of follow-up } \\
\text { time-points }\end{array}$ & $\begin{array}{c}\text { Follow-up } \\
\text { interval (years) }\end{array}$ & Covariates & $\begin{array}{c}\text { Whole-brain/ } \\
\text { targets }\end{array}$ \\
\hline $\begin{array}{l}\text { Farrow et al., } \\
2005^{15}\end{array}$ & Australia & $\begin{array}{l}25 \mathrm{FES} \\
22 \mathrm{HC}\end{array}$ & $\begin{array}{l}19.5 \\
20.5\end{array}$ & 1 & 2.5 & Age & $\begin{array}{l}\text { Frontal GM; } \\
\text { Temporal GM; } \\
\text { Cerebellum }\end{array}$ \\
\hline $\begin{array}{l}\text { Whitford et al., } \\
2006^{16}\end{array}$ & Australia & $\begin{array}{l}25 \mathrm{FEP} \\
26 \mathrm{HC}\end{array}$ & $\begin{array}{l}19.8 \\
19.3\end{array}$ & 1 & 2.5 & $\begin{array}{l}\text { Age; Gender; } \\
\text { Handedness; } \\
\text { Follow-up interval }\end{array}$ & Total brain \\
\hline $\begin{array}{l}\text { Sun et al., } \\
2008^{30}\end{array}$ & Australia & $\begin{array}{l}16 \mathrm{FEP} \\
14 \mathrm{HC}\end{array}$ & $\begin{array}{l}21.8 \\
21.1\end{array}$ & 1 & 2 & Inter-scan interval & $\begin{array}{c}\text { Brain surface } \\
\text { contraction }\end{array}$ \\
\hline $\begin{array}{l}\text { Mane et al., } \\
2009^{17}\end{array}$ & España & $\begin{array}{l}15 \mathrm{FEP} \\
11 \mathrm{HC}\end{array}$ & No reported & 1 & 4 & $\begin{array}{l}\text { Age at first scan; } \\
\text { Follow-up interval; } \\
\text { Whole brain volume }\end{array}$ & $\begin{array}{l}\text { STG; Orbitofrontal } \\
\text { gyrus; } \\
\text { Lingual gyrus; Cuneus }\end{array}$ \\
\hline $\begin{array}{l}\text { Asami et al., } \\
2012^{18}\end{array}$ & USA & $\begin{array}{l}21 \mathrm{FEP} \\
23 \mathrm{HC}\end{array}$ & $\begin{array}{l}25 \\
24.2\end{array}$ & 1 & 1.5 & No reported & $\begin{array}{l}\text { Frontal GM; } \\
\text { Temporal GM } \\
\text { Parietal GM; } \\
\text { Cerebellum }\end{array}$ \\
\hline
\end{tabular}

FES: first episode of schizophrenia, FEP: first episode of psychosis, HC: healthy control, GM: grey matter, STG: superior temporal gyrus

differences in total temporal lobe or STG volumes between FEP patients and healthy controls at any of two temporal points: after 5 and 10 years of follow-up.

\section{ROI manual tracing}

Firstly, in the study by Kasai et al., ${ }^{20}$ although the groups did not differ significantly with respect to the amygdala-hippocampus complex, the FEP group showed a more significant decrease in GM volume in the left posterior STG than the healthy control group, after 1.5 years since the first scan. In an extension of the previous study, ${ }^{21}$ Kasai et al. ${ }^{20}$ found that the FEP group presented a GM reduction in the left HG and left planum temporal (PT) after 1.5 years since the first scan. FEP patients showed a smaller GM volume in the left HG compared with the control group. Regarding to PT, patients presented a GM reduction in the left PT relative to controls.

Results of the study by Nakamura et al. ${ }^{7}$ revealed reductions in neocortical grey matter (NCGM). FEP group showed a lower volume in temporal and frontal lobes, but did not differ in the parieto-occipital lobe, in comparison to the controls after 1.5 years since baseline. This study showed that groups differed in lateral ventricles (LV) volume changes. The results determined greater enlargement of total LV in FEP group compared with controls.

The study by Koo et al. ${ }^{22}$ was found that the FEP group showed a progressive GM volume reduction in regions of the cingulate gyrus (CG), specifically in the bilateral posterior cingulate gyrus (PGC) and anterior cingulate gyrus (ACG) (subgenual, affective and cognitive) at time 2 compared with time 1 after the first scan (mean: 1.5 years). The study by Lee et al. ${ }^{23}$ showed that the GM volume in bilateral insular cortex and temporal lobe, was significantly decreased after 1.5 years between the first and second scan in the FEP group compared with the control group.

This review included four studies by Takahashi and his team. Two studies were performed with different samples of patients and controls from Australia, and two studies with a sample from Japan. The first study by Takahashi et al., ${ }^{24}$ with an Australian sample, showed that the FEP patients had greater GM reduction of the insular cortex bilaterally after 2 years of follow-up compared with controls.

In the second study with an Australian sample, carried out in $2009,{ }^{25}$ they found that the FEP patients showed significant GM loss in the left planum polare (PP), left HG, PT, left rostral STG, and left caudal STG after 1.8 years (on average) since the first scan.

In the third study, ${ }^{8} \mathrm{GM}$ of the STG subregions [planum polare (PP), HG, PT, rostral STG, and caudal STG] were manually traced. The results showed that the FEP patients had a greater STG reduction compared with controls after followup (mean: 2.7 years). Likewise, the FEP group showed greater GM loss of the left HG and bilateral caudal STG versus healthy controls. However, there were no significant differences between groups in the volume change of the whole grey matter. The fourth study by Takahashi et al., ${ }^{26}$ carried out with the same sample as the third study, revealed that for the fusiform gyrus, the FEP group showed a greater GM decrease than the controls at time 2 compared with time 1 after first scan (mean: 2.7 years). However, it did not show a GM decrease in the middle and inferior temporal gyri. 
Table 2. Region of interest

\begin{tabular}{|c|c|c|c|c|c|c|c|}
\hline $\begin{array}{c}\text { Authors/ } \\
\text { year }\end{array}$ & Country & Sample & $\begin{array}{l}\text { Age first } \\
\text { scan }\end{array}$ & $\begin{array}{l}\text { Num. of follow-up } \\
\text { time-points }\end{array}$ & $\begin{array}{c}\text { Follow-up } \\
\text { interval (years) }\end{array}$ & Covariates & Whole-brain/targets \\
\hline \multirow{2}{*}{$\begin{array}{l}\text { Kasai et al., } \\
2003^{20}\end{array}$} & \multirow[t]{2}{*}{ USA } & $13 \mathrm{FEP}$ & 27.2 & \multirow[t]{2}{*}{1} & \multirow[t]{2}{*}{1.5} & \multirow{2}{*}{$\begin{array}{l}\text { Age; Inter scan } \\
\text { interval }\end{array}$} & \multirow{2}{*}{$\begin{array}{l}\text { STG; Amygdala } \\
\text { hippocampal complex }\end{array}$} \\
\hline & & $14 \mathrm{HC}$ & 25.6 & & & & \\
\hline \multirow{2}{*}{$\begin{array}{l}\text { Kasai et al., } \\
2003^{21}\end{array}$} & \multirow[t]{2}{*}{ USA } & $13 \mathrm{FEP}$ & 27.3 & \multirow[t]{2}{*}{1} & \multirow[t]{2}{*}{1.5} & Age; Inter scan & \multirow[t]{2}{*}{ HG; PT } \\
\hline & & $22 \mathrm{HC}$ & 25 & & & interval & \\
\hline \multirow{2}{*}{$\begin{array}{l}\text { DeLisi and Hoff } \\
2005^{19}\end{array}$} & \multirow[t]{2}{*}{ USA } & $27 \mathrm{FEP}$ & No reported & \multirow[t]{2}{*}{2} & \multirow[t]{2}{*}{$5-10$} & Age; Gender; Total & \multirow[t]{2}{*}{ Temporal lobe } \\
\hline & & $10 \mathrm{HC}$ & & & & brain volume & \\
\hline \multirow{2}{*}{$\begin{array}{l}\text { Salisbury et al., } \\
2007^{27}\end{array}$} & \multirow[t]{2}{*}{ USA } & $20 \mathrm{FEP}$ & 24.5 & \multirow[t]{2}{*}{1} & \multirow[t]{2}{*}{1.5} & No reported & \multirow[t]{2}{*}{ Temporal lobe } \\
\hline & & $32 \mathrm{HC}$ & 24.1 & & & & \\
\hline \multirow{2}{*}{$\begin{array}{l}\text { Nakamura et al., } \\
2007^{7}\end{array}$} & \multirow[t]{2}{*}{ USA } & $17 \mathrm{FEP}$ & 24.7 & \multirow[t]{2}{*}{1} & \multirow[t]{2}{*}{$1.5^{*}$} & \multirow[t]{2}{*}{ No reported } & \multirow{2}{*}{$\begin{array}{l}\text { Frontal, temporal and } \\
\text { parieto-occipital lobes }\end{array}$} \\
\hline & & $26 \mathrm{HC}$ & 23.6 & & & & \\
\hline \multirow{2}{*}{$\begin{array}{l}\text { Koo et al., } \\
2008^{22}\end{array}$} & \multirow[t]{2}{*}{ USA } & $17 \mathrm{FEP}$ & 24.6 & \multirow[t]{2}{*}{1} & \multirow[t]{2}{*}{1.5} & Inter-scan interval; & \multirow[t]{2}{*}{ CG } \\
\hline & & $18 \mathrm{HC}$ & 23.4 & & & ICC & \\
\hline \multirow{2}{*}{$\begin{array}{l}\text { Takahashi et al., } \\
2009^{24}\end{array}$} & Australia & $23 \mathrm{FEP}$ & 21.6 & & 2 & Age; Gender; ICV & Insular cortex \\
\hline & & $26 \mathrm{HC}$ & 25.6 & 1 & 2.2 & & (Volume) \\
\hline Takahashi et al. & Australia & $23 \mathrm{FEP}$ & 21.6 & 1 & $1.8^{*}$ & Age; Inter-scan & STG [(PP); (HG); (PT); \\
\hline $2009^{25}$ & & $22 \mathrm{HC}$ & 22.0 & & & interval & $\begin{array}{l}\text { rostral STG; caudal } \\
\text { STG] }\end{array}$ \\
\hline & Japan & 18 FEP & 23.1 & 1 & $2.7^{*}$ & Age; Inter-scan & STG [subregions (PP), \\
\hline $2010^{8}$ & жариі & $20 \mathrm{HC}$ & 23.2 & & & interval; IVC; & (HG), (PT), rostral \\
\hline & & & & & & treatment & STG, and caudal STG] \\
\hline Takahashi et al. & Japan & $18 \mathrm{FEP}$ & 23.1 & 1 & $2.7^{*}$ & Age, Inter-scan & Fusiform gyrus; middle \\
\hline $2011^{26}$ & & $20 \mathrm{HC}$ & 23.2 & & & interval; IVC; & and inferior temporal \\
\hline & & & & & & treatment & gyrus \\
\hline Lee et al., & USA & 22 FEP & 25.3 & 1 & 1.5 & No reported & Insular Gyrus; \\
\hline $2015^{23}$ & & $23 \mathrm{HC}$ & 24.2 & & & & Temporal Pole \\
\hline
\end{tabular}

*on average. FEP: first episode of psychosis, HC: healthy control, ICV and IVC: intracraneal volume, STG: superior temporal gyrus, HG: heschl gyrus, PT: planum temporal, CG: cingulate gyrus, PP: planum polare

Table 3. Image Processing Laboratory, University of lowa Hospitals and Clinics, USA BRAINS2

\begin{tabular}{|c|c|c|c|c|c|c|c|}
\hline $\begin{array}{c}\text { Authors/ } \\
\text { year }\end{array}$ & Country & Sample & $\begin{array}{l}\text { Age first } \\
\text { scan }\end{array}$ & $\begin{array}{l}\text { Num of follow-up } \\
\text { time-points }\end{array}$ & $\begin{array}{c}\text { Follow-up } \\
\text { interval (years) }\end{array}$ & Covariates & Whole-brain/targets \\
\hline $\begin{array}{l}\text { Andreasen et al., } \\
2011^{28}\end{array}$ & USA & $\begin{array}{l}202 \mathrm{FEP} \\
125 \mathrm{HC}\end{array}$ & No reported & 3 & $2-3-4$ & $\begin{array}{l}\text { Intracranial volume } \\
\text { at initial MR scan; } \\
\text { imaging protocol } \\
\text { (MR5, MR6); Age }\end{array}$ & Total brain \\
\hline $\begin{array}{l}\text { Roiz-Santianez } \\
\text { et al., } 2014^{9}\end{array}$ & Spain & $\begin{array}{c}109 \mathrm{FEP} \\
76 \mathrm{HC}\end{array}$ & $\begin{array}{l}29.44 \\
27.80\end{array}$ & 2 & $1-3$ & Age; Gender & Total brain \\
\hline $\begin{array}{l}\text { Roiz-Santianez } \\
\text { et al., } 2015^{29}\end{array}$ & Spain & $\begin{array}{c}109 \mathrm{FEP} \\
79 \mathrm{HC}\end{array}$ & $\begin{array}{l}29.44 \\
27.80\end{array}$ & 2 & $1-3$ & Age; Gender & Cortical thickness \\
\hline
\end{tabular}

FEP: first episode of psychosis, HC: healthy control, MR: magnetic resonance

In the research by Salisbury et al., ${ }^{27}$ they observed that the FEP group showed an HG volume reduction in comparison with healthy controls after 1.5 years of follow-up. This study reported on the correlation between longitudinal GM reduction in HG and mismatch negativity (MMN), a biomarker of SSD.

\section{BRAINS2}

Included in the ROI technique, the software package BRAINS2 (Image Processing Laboratory, University of Iowa Hospitals and Clinics, USA), is a semi-automated technique which provides measurements of cortical gyrification, brain tissue compartments (GM, white matter, and cerebrospinal fluid), and 
Table 4. Results

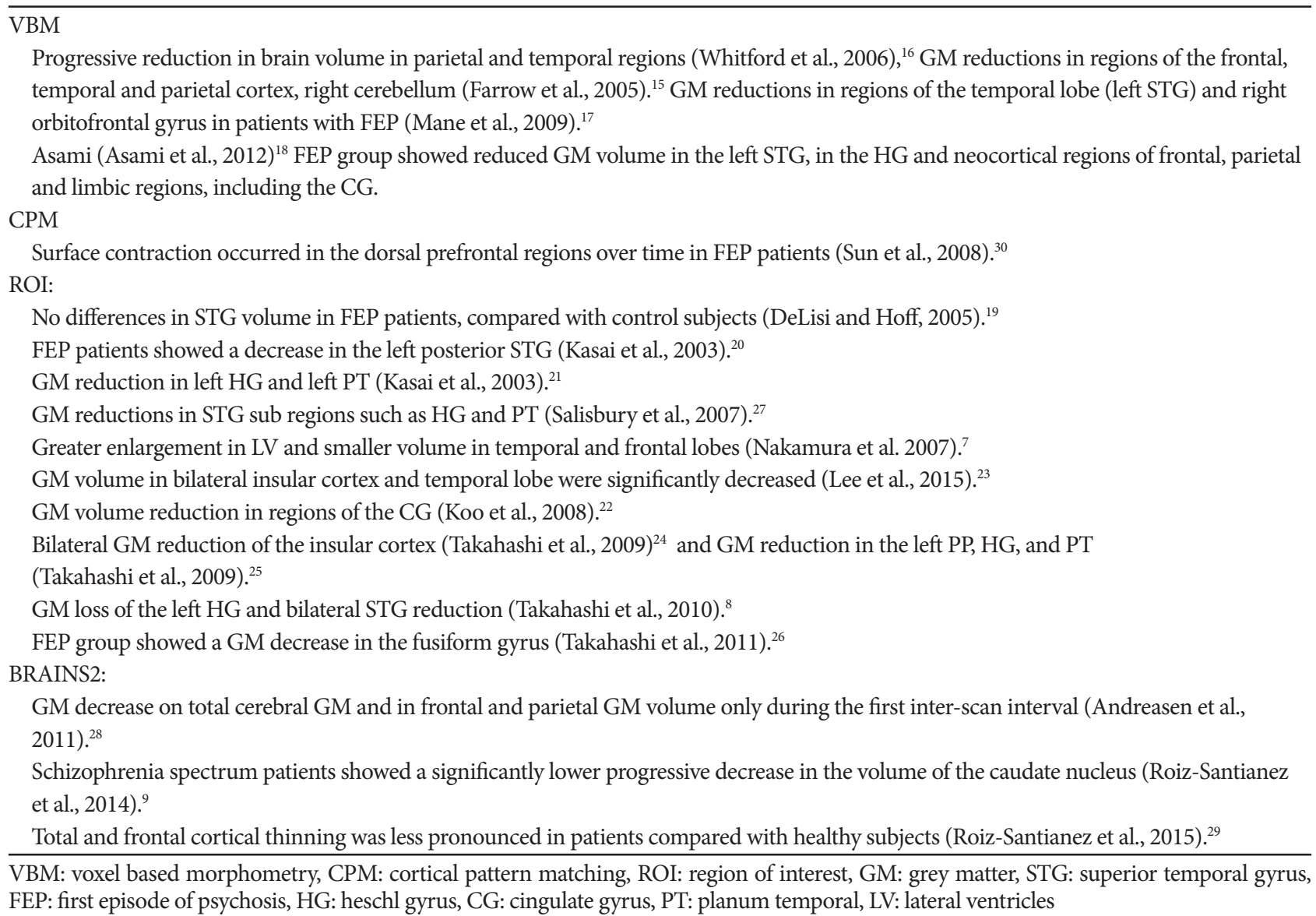

specific brain substructures. For instance, it is possible to measure the surface area, left and right hemisphere differences, curvature indices of gyri and sulci, or cortical thickness.

Using BRAINS2, we have identified three studies. The article by Andreasen et al., ${ }^{28}$ determined that patients with SSD had a greater loss than healthy controls on total cerebral GM, frontal, temporal and parietal GM volumes 2 years after the baseline.

A study by Roiz-Santianez et al. ${ }^{9}$ found an overall GM loss in FEP patients and healthy controls over time. Patients and control subjects showed a similar pattern of brain changes. However, the caudate nucleus of healthy subjects showed a greater reduction than patients during the 3-year follow-up period.

Recently, in a new study with the same sample, Roiz-Santianez et al. ${ }^{29}$ investigated measurement of cortical thickness. The results showed that total and frontal cortical thinning was less pronounced during the early course of the illness -3 year follow-up period-in patients compared with healthy subjects.

\section{Cortical pattern matching}

Only one study used the CPM technique. With this method, cortical anatomy can be compared with measure differ- ences across subjects and across time. CPM involves creating a 3D geometric model of the cortical surface extracted from the MRI volume. Using this procedure, algorithms are applied for measuring cortical thickness, and detect GM abnormalities in patients with schizophrenia.

This study refers to the brain surface contraction related to psychosis. ${ }^{30}$ The results showed a relationship between the contraction of the brain surface, and the progressive reduction of GM in patients with FEP. They found that in the FEP group, surface contraction occurred in the dorsal prefrontal and parietal regions over time. In the between-groups comparison, the FEP group showed significantly greater brain surface contraction in the right superior frontal gyrus and the left middle frontal gyri, and in the right pre-/postcentral gyri and adjacent parietal regions. These results were found 2 years after the first scan.

\section{DISCUSSION}

We have focused especially on brain structure evolution after the first years of the illness, selecting 19 studies of duration of more than 1 year between assessments, and using different 
methods of image analysis. Most of the results included in this review show a progressive reduction in cortical GM volume in FEP. However, GM reduction is not uniform in the whole brain. As such, numerous studies have investigated different regions involved in the course of SSD, which are discussed below.

\section{Frontal regions}

Seven articles showed GM reductions in frontal lobe areas. Specifically, changes in the frontal cortex ${ }^{15}$ and right orbitofrontal gyrus ${ }^{17}$ have been observed in patients with FEP. In the studies by Nakamura et al. ${ }^{7}$ and Asami et al., ${ }^{18}$ FEP patients showed a lower frontal GM volume than healthy controls. However, there is evidence that a subset of brain abnormalities may change over the course of the illness. Results of the research by Andreasen et al. ${ }^{28}$ revealed significant results at different times in their research with a larger sample. This study has three time points after the first scan. The authors found that frontal GM in patients with schizophrenia differed significantly from healthy controls during the first inter-scan interval ( 2 years between baseline and second point); but not during the following intervals, 3 and 4 years after the baseline. These results showed a progressive decrease in GM only during the first years of schizophrenia. It is important to highlight that the data refer to the largest sample included in this review. The progression of GM changes may be influenced by the sample size.

Regarding cortical thickness, the study by Roiz-Santianez et al. ${ }^{29}$ showed a significant cortical thinning in patients in total brain and frontal GM at baseline in studies with a larger sample. However, it also found a greater thinning over time in the control group. Specifically, total and frontal cortical thinning was less pronounced in patients compared with healthy subjects. Contrary to these results, others studies showed reduced cortical thickness in frontal regions in first-episode schizophrenia patients. ${ }^{31,32}$ It is important to mention that cortical thickness has been related to cognitive dysfunction in FEP patients. ${ }^{33}$

In the only study about brain surface contraction in early $\mathrm{SSD},{ }^{30}$ the authors found that surface contraction occurred in the dorsal prefrontal regions over time in FEP patients. These results suggest a significant correlation between brain surface contraction and GM decrease in the cortical surface, consistent with the results observed in previous studies. ${ }^{31}$ Evidence suggests that GM reduction in the prefrontal cortex is related to impairments in cognition, conceptual thinking, verbal memory, ${ }^{6,34}$ and working memory. ${ }^{35}$ Recently, studies suggested a prefrontal dysfunction as a cause of executive function deficit in SSD patients. ${ }^{36,37}$

\section{Parietal regions}

In relation to the parietal lobes (PL), six studies investigated changes in GM in this region in FEP patients. In compari- son with controls, five studies revealed that the FEP group showed differences in GM volume over time..$^{15,16,18,28,30}$ However, in the study by Nakamura et al., ${ }^{7}$ FEP patients did not show a GM decrease in the parieto-occipital lobe. Parietal lobes are involved in neuropsychological functions which are affected in SSD patients, such as attentional and memory dysfunctions or impairments of motor control. ${ }^{38}$ Studies of patients with SSD have found a decrease in GM volume in the $\mathrm{PL}$ and its correlation with cognitive performance in the early course of SSD, ${ }^{39,40}$ as well as its association with psychotic experiences. $^{41}$

\section{Temporal and occipital regions}

$58 \%$ of the selected longitudinal studies have found a progressive reduction in brain volume in the early years of the disease in temporal regions, ${ }^{15,16,23,28}$ including GM reductions in STG, ${ }^{17,18,20}$ subregions HG and PT). ${ }^{8,21,25,27}$ The results showed that FEP patients have a greater decrease in GM in this region. However, in the study of DeLisi and Hoff ${ }^{19}$ ten years after the first scan, the results showed no differences in STG volume in FEP patients, compared with control group. The study by Andreasen et al. ${ }^{28}$ showed a GM reduction in the first years but not in the later years. This pattern may be affected due to the larger sample size. With respect to this, studies have determined that SSD patients show more severe impairment in attention, as well as in verbal and visual learning. ${ }^{42}$ Therefore, morphological abnormalities of the STG related to SSD have been reported in numerous studies. ${ }^{25,43,44}$ However, most recent research in this area showed conflicting results. The study by Schaufelberger et al. ${ }^{45}$ revealed a GM increase in the left STG in FEP patients, suggesting a reversible course in the STG during the illness.

Related to the occipital lobe, in this review we found a study ${ }^{17}$ which showed an increase in bilateral lingual gyrus and right cuneus in FEP patients, in contrast with the results suggesting a positive relationship between schizophrenia and impairment in visual function.

\section{Subcortical structures}

The subcortical regions have been examined in several studies, and we found controversial results. GM reductions of the cingulate and fusiform gyrus, ${ }^{22,26}$ were found in FEP. Interestingly, most of the results of this review determined that FEP patients did not show volume decreases in subcortical regions over the follow-up interval. In the study by Asami et al., ${ }^{18}$ FEP patients showed a GM reduction in limbic regions, such as the bilateral insula. Kasai et al. ${ }^{20}$ determined that the groups do not significantly differ as far as the amygdala-hippocampus volume is concerned. In particular, Roiz-Santianez et al., ${ }^{9}$ with a larger sample than others studies, found that the caudate nu- 
cleus of control subjects showed a reduction compared with the FEP patients.

Regarding the insular lobe, in the study by Takahashi et al., ${ }^{24}$ patients with FEP showed a bilateral GM reduction of the insular cortex. Likewise, in a recent study by Lee et al., ${ }^{23}$ bilateral insular cortex and temporal lobe GM decreased over time in the early course of psychosis. The insular connection with the limbic system makes it an object of study in SSD. Also, there is evidence of the positive relationship between a GM decrease in this region with emotional and cognitive dysfunctions in patients with $\mathrm{FEP}^{46}$ and severity of clinical symptoms. ${ }^{47}$

Previous longitudinal studies suggest that these conflicting results can be influenced by treatment effects. ${ }^{48}$ In this review, FEP patients have been exposed to different treatments. However, apart from treatment effects, there is evidence to support the reductions in these regions in SSD patients. Specifically, abnormalities in GM in frontal, temporal, and subcortical regions, such as the basal ganglia, thalamus, and hippocampal complex, have been associated with learning, motor, and emotional impairments in patients with SSD. Therefore, dysfunctions in limbic system have been connected to language processing impairment in SDD. ${ }^{49}$ Furthermore, the limbic system is responsible for the response and memory of emotions, functions which are affected in patients with SSD..$^{50,51}$

Recently, in relation to the changes that occurred in the subcortical region, a meta-analysis by the ENIGMA consortium, with 2028 SSD patients and 2540 healthy controls, determined that patients with SSD had smaller hippocampus, amygdala, thalamus, and accumbens volumes than healthy controls. ${ }^{52}$

\section{Cerebellum}

There are two studies showing a GM decrease in the cerebellum in FEP patients compared with healthy individuals. ${ }^{15,16}$ Here, it is important to take into account the role of the cerebellum in motor, cognition, and affective functions. ${ }^{53,54}$ Longitudinal studies in patients at risk of SSD observed that cerebellar regions show anatomical and functional alterations in the onset of illness. ${ }^{55}$ Previous findings support that motor function and postural control, ${ }^{56,57}$ the modulation of affect and emotion, ${ }^{58}$ and cognition functions ${ }^{59}$ are affected in the course of SSD. On the other hand, there is evidence for the relationship between cerebellar dysfunction and psychiatric symptoms. ${ }^{60}$ One important author in this context is Andreasen, and her theory called "cognitive dysmetria," which suggests a dysfunction in the integration of cortical-subcortical-cerebellar connection. ${ }^{61}$ Specifically, the cognitive dysmetria hypothesis determined that this dysfunction involves cerebellar and subcortical circuits in alterations in the motor, cognitive, and social functions present in the patients with SSD. ${ }^{62}$

\section{Lateral ventricle volume}

Related to LV, in this review, we found that in the study by Nakamura et al., FEP patients showed greater enlargement in LV and smaller volume in temporal and frontal lobes than controls. Structural neuroimaging studies have investigated an association between SSD and abnormalities in brain morphology, such as ventricular enlargement. ${ }^{43,63,64}$ Ventricular enlargement is one of the most common findings in studies focused on research into SSD, and numerous studies have suggested a ventricular enlargement in patients with FEP and SSD, ${ }^{65-67}$ and longitudinal studies revealed a progressive ventricular enlargement ${ }^{68-70}$ related to progressive reduction of $\mathrm{GM}^{71}$

\section{Strengths and limitations}

An advantage of this review is that it collected information about global and regional GM volume changes during the first stages of illness, with the aim of obtaining comparable results. These findings enable us to recognize the areas involved in the disease and its relationship with it to achieve better early intervention in the course of the disease. We provide a global perspective of the research between FEP and progressive GM decrease. Furthermore, this review explores the different existing techniques applied to the field of psychiatry; specifically, in SSD. Despite these strengths, this study has several limitations. We did not focus on the relationship between GM changes and different treatments or effects of medication. We did not include the effects in the results of age, gender race, or ethnicity, during the follow-up interval. Finally, this review included studies that have a follow-up period that is longer than 1.5 years to observe progressive changes in the onset of illness. Articles with an interval between assessments equal or less than 1 year were not included.

\section{CONCLUSION}

In summary, the present review of longitudinal studies provides evidence that there is a relationship between the cortical reductions of GM reported in MRI studies and the early course of SSD. These findings indicate wide-spread decreases in grey matter through the brain. These results could be related to causes as medication, function or cognition. Longer follow-up studies in large cohorts are needed in order to shed more light in grey matter progression in the first years after the onset of illness and its clinical correlates. Future research will try to find out the implication that these results may have on the clinical evolution of the disease.

\section{REFERENCES}

1. Insel TR. Rethinking schizophrenia. Nature 2010;468:187-193. 
2. Weinberger DR. Implications of normal brain development for the pathogenesis of schizophrenia. Arch Gen Psychiatry 1987;44:660-669.

3. Wright IC, Rabe-Hesketh S, Woodruff PW, David AS, Murray RM, Bullmore ET. Meta-analysis of regional brain volumes in schizophrenia. Am J Psychiatry 2000;157:16-25.

4. Woods BT, Ward KE, Johnson EH. Meta-analysis of the time-course of brain volume reduction in schizophrenia: implications for pathogenesis and early treatment. Schizophr Res 2005;73:221-228.

5. Steen RG, Mull C, Mcclure R, Hamer RM, Lieberman JA. Brain volume in first-episode schizophrenia. Br J Psychiatry 2006;188:510-518.

6. Zipparo L, Whitford TJ, Redoblado Hodge MA, Lucas S, Farrow TF, Brennan J, et al. Investigating the neuropsychological and neuroanatomical changes that occur over the first 2-3 years of illness in patients with first-episode schizophrenia. Prog Neuropsychopharmacol Biol Psychiatry 2008;32:531-538.

7. Nakamura M, Salisbury DF, Hirayasu Y, Bouix S, Pohl KM, Yoshida T, et al. Neocortical gray matter volume in first-episode schizophrenia and first-episode affective psychosis: a cross-sectional and longitudinal MRI study. Biol Psychiatry 2007;62:773-783.

8. Takahashi T, Suzuki M, Zhou SY, Tanino R, Nakamura K, Kawasaki Y, et al. A follow-up MRI study of the superior temporal subregions in schizotypal disorder and first-episode schizophrenia. Schizophr Res 2010;119: 65-74.

9. Roiz-Santianez R, Ayesa-Arriola R, Tordesillas-Gutierrez D, Ortiz-Garcia de la Foz V, Perez-Iglesias R, Pazos A, et al. Three-year longitudinal population-based volumetric MRI study in first-episode schizophrenia spectrum patients. Psychol Med 2014;44:1591-1604.

10. Loebel AD, Lieberman JA, Alvir JM, Mayerhoff DI, Geisler SH, Szymanski SR. Duration of psychosis and outcome in first-episode schizophrenia. Am J Psychiatry 1992;149:1183-1188.

11. Ashburner J, Friston KJ. Voxel-based morphometry-the methods. Neuroimage 2000;11:805-821.

12. Magnotta VA, Harris G, Andreasen NC, O'Leary DS, Yuh WT, Heckel D. Structural MR image processing using the BRAINS2 toolbox. Comput Med Imaging Graph 2002;26:251-264.

13. Thompson PM, MacDonald D, Mega MS, Holmes CJ, Evans AC, Toga AW. Detection and mapping of abnormal brain structure with a probabilistic atlas of cortical surfaces. J Comput Assist Tomogr 1997;21:567581.

14. Moher D, Liberati A, Tetzlaff J, Altman DG; PRISMA Group. Preferred reporting items for systematic reviews and meta-analyses: the PRISMA statement. Int J Surg 2010;8:336-341.

15. Farrow TF, Whitford TJ, Williams LM, Gomes L, Harris AW. Diagnosis-related regional gray matter loss over two years in first episode schizophrenia and bipolar disorder. Biol Psychiatry 2005;58:713-723.

16. Whitford TJ, Grieve SM, Farrow TF, Gomes L, Brennan J, Harris AW, et al. Progressive grey matter atrophy over the first 2-3 years of illness in first-episode schizophrenia: a tensor-based morphometry study. Neuroimage 2006;32:511-519.

17. Mane A, Falcon C, Mateos JJ, Fernandez-Egea E, Horga G, Lomena F, et al. Progressive gray matter changes in first episode schizophrenia: a 4-year longitudinal magnetic resonance study using VBM. Schizophr Res 2009;114:136-143.

18. Asami T, Bouix S, Whitford TJ, Shenton ME, Salisbury DF, McCarley RW. Longitudinal loss of gray matter volume in patients with first-episode schizophrenia: DARTEL automated analysis and ROI validation. Neuroimage 2012;59:986-996.

19. DeLisi LE, Hoff AL. Failure to find progressive temporal lobe volume decreases 10 years subsequent to a first episode of schizophrenia. Psychiatry Res 2005;138:265-268.

20. Kasai K, Shenton ME, Salisbury DF, Hirayasu Y, Lee CU, Ciszewski AA, et al. Progressive decrease of left superior temporal gyrus gray matter volume in patients with first-episode schizophrenia. Am J Psychiatry 2003;160:156-164.

21. Kasai K, Shenton ME, Salisbury DF, Hirayasu Y, Onitsuka T, Spencer
$\mathrm{MH}$, et al. Progressive decrease of left Heschl gyrus and planum temporale gray matter volume in first-episode schizophrenia: a longitudinal magnetic resonance imaging study. Arch Gen Psychiatry 2003;60:766775 .

22. Koo M-S, Levitt JJ, Salisbury DF, Nakamura M, Shenton ME, McCarley RW. A cross-sectional and longitudinal magnetic resonance imaging study of cingulate gyrus gray matter volume abnormalities in first-episode schizophrenia and first-episode affective psychosis. Arch Gen Psychiatry 2008;65:746-760.

23. Lee SH, Niznikiewicz M, Asami T, Otsuka T, Salisbury DF, Shenton ME, et al. Initial and progressive gray matter abnormalities in insular gyrus and temporal pole in first-episode schizophrenia contrasted with firstepisode affective psychosis. Schizophr Bull 2016;42:790-801.

24. Takahashi T, Wood SJ, Soulsby B, McGorry PD, Tanino R, Suzuki M, et al. Follow-up MRI study of the insular cortex in first-episode psychosis and chronic schizophrenia. Schizophr Res 2009;108:49-56.

25. Takahashi T, Wood SJ, Yung AR, Soulsby B, McGorry PD, Suzuki M, et al. Progressive gray matter reduction of the superior temporal gyrus during transition to psychosis. Arch Gen Psychiatry 2009;66:366-376.

26. Takahashi T, Zhou SY, Nakamura K, Tanino R, Furuichi A, Kido M, et al. A follow-up MRI study of the fusiform gyrus and middle and inferior temporal gyri in schizophrenia spectrum. Prog Neuro-psychopharmacol Biol Psychiatry 2011;35:1957-1964.

27. Salisbury DF, Kuroki N, Kasai K, Shenton ME, McCarley RW. Progressive and interrelated functional and structural evidence of post-onset brain reduction in schizophrenia. Arch Gen Psychiatry 2007;64:521-529.

28. Andreasen NC, Nopoulos P, Magnotta V, Pierson R, Ziebell S, Ho BC. Progressive brain change in schizophrenia: a prospective longitudinal study of first-episode schizophrenia. Biol Psychiatry 2011;70:672-679.

29. Roiz-Santianez R, Ortiz-Garcia de la Foz V, Ayesa-Arriola R, TordesillasGutierrez D, Jorge R, Varela-Gomez N, et al. No progression of the alterations in the cortical thickness of individuals with schizophrenia-spectrum disorder: a three-year longitudinal magnetic resonance imaging study of first-episode patients. Psychol Med 2015;45:2861-2871.

30. Sun D, Stuart GW, Jenkinson M, Wood SJ, McGorry PD, Velakoulis D, et al. Brain surface contraction mapped in first-episode schizophrenia: a longitudinal magnetic resonance imaging study. Mol Psychiatry 2009; 14:976-986.

31. Schultz CC, Koch K, Wagner G, Roebel M, Schachtzabel C, Gaser C, et al. Reduced cortical thickness in first episode schizophrenia. Schizophr Res 2010;116:204-209.

32. Cannon TD, Chung Y, He G, Sun D, Jacobson A, Van Erp TG, et al. Progressive reduction in cortical thickness as psychosis develops: a multisite longitudinal neuroimaging study of youth at elevated clinical risk. Biol Psychiatry 2015;77:147-157.

33. Haring L, Müürsepp A, Mõttus R, Ilves P, Koch K, Uppin K, et al. Cortical thickness and surface area correlates with cognitive dysfunction among first-episode psychosis patients. Psychol Med 2016;46:21452155.

34. Hill SK, Beers SR, Kmiec JA, Keshavan MS, Sweeney JA. Impairment of verbal memory and learning in antipsychotic-nave patients with firstepisode schizophrenia. Schizophr Res 2004;68:127-136.

35. Oram J, Geffen GM, Geffen LB, Kavanagh DJ, McGrath JJ. Executive control of working memory in schizophrenia. Psychiatry Res 2005;135: 81-90.

36. Orellana G, Slachevsky A. Executive functioning in schizophrenia. Front Psychiatry 2013;4:35.

37. Haatveit B, Vaskinn A, Sundet KS, Jensen J, Andreassen OA, Melle I, et al. Stability of executive functions in first episode psychosis: One year follow up study. Psychiatry Res 2015;228:475-481.

38. Bellani M, Ferro A, Brambilla P. The potential role of the parietal lobe in schizophrenia. Epidemiol Psychiatr Sci 2010;19:118-119.

39. Minatogawa-Chang TM, Schaufelberger MS, Ayres AM, Duran FL, Gutt EK, Murray RM, et al. Cognitive performance is related to cortical grey matter volumes in early stages of schizophrenia: a population-based 
study of first-episode psychosis. Schizophr Res 2009;113:200-209.

40. Ferro A, Roiz-Santiáñez R, de la Foz VO-G, Tordesillas-Gutiérrez D, Ayesa-Arriola R, de La Fuente-González N, et al. A cross-sectional and longitudinal structural magnetic resonance imaging study of the postcentral gyrus in first-episode schizophrenia patients. Psychiatry Res Neuroimag 2015;231:42-49.

41. Yildiz M, Borgwardt SJ, Berger GE. Parietal lobes in schizophrenia: do they matter? Schizophr Res Treatment 2011;2011:581686.

42. Kalkstein S, Hurford I, Gur RC. Neurocognition in Schizophrenia. In: Swerdlow NR, Editor. Behavioral Neurobiology of Schizophrenia and Its Treatment. Berlin: Springer, 2010, p. 373-390.

43. Cahn W, Pol HEH, Lems EB, van Haren NE, Schnack HG, van der Linden JA, et al. Brain volume changes in first-episode schizophrenia: a 1-year follow-up study. Arch Gen Psychiatry 2002;59:1002-1010.

44. Vita A, De Peri L, Deste G, Sacchetti E. Progressive loss of cortical gray matter in schizophrenia: a meta-analysis and meta-regression of longitudinal MRI studies. Transl Psychiatry 2012;2:e190.

45. Schaufelberger M, Lappin J, Duran F, Rosa P, Uchida R, Santos L, et al. Lack of progression of brain abnormalities in first-episode psychosis: a longitudinal magnetic resonance imaging study. Psychol Med 2011;41: 1677-1689.

46. Crespo-Facorro B, Kim JJ, Andreasen NC, O'Leary DS, Bockholt HJ, Magnotta V. Insular cortex abnormalities in schizophrenia: a structural magnetic resonance imaging study of first-episode patients. Schizophr Res 2000;46:35-43.

47. Pang L, Kennedy D, Wei Q, Lv L, Gao J, Li H, et al. Decreased Functional Connectivity of Insular Cortex in Drug Nä̈ve First Episode Schizophrenia: In Relation to Symptom Severity. PLoS one 2017;12:e0167242.

48. Levitt JJ, Bobrow L, Lucia D, Srinivasan P. A Selective Review of Volumetric and Morphometric Imaging in Schizophrenia. In: Swerdlow NR, Editor. Behavioral Neurobiology of Schizophrenia and Its Treatment. Berlin: Springer, 2010, p. 243-281.

49. Li X, Black M, Xia S, Zhan C, Bertisch HC, Branch CA, et al. Subcortical structure alterations impact language processing in individuals with schizophrenia and those at high genetic risk. Schizophr Res 2015;169: 76-82.

50. Fernández-Egea E, Parellada Rodon E, Lomeña Caballero F, Mané Santacana A, Bernardo Arroyo M. Papel de la amígdala en el reconocimiento facial de las emociones en la esquizofrenia. Psiquiatr Biol 2007; 14:31-39.

51. Anticevic A, Van Snellenberg JX, Cohen RE, Repovs G, Dowd EC, Barch DM. Amygdala recruitment in schizophrenia in response to aversive emotional material: a meta-analysis of neuroimaging studies. Schizophr Bull 2012;38:608-621.

52. Okada N, Fukunaga M, Yamashita F, Koshiyama D, Yamamori H, Ohi $\mathrm{K}$, et al. Abnormal asymmetries in subcortical brain volume in schizophrenia. Mol Psychiatry. 2016;21:1460-1466.

53. Barrios M, Guardia J. Relation of the cerebellum with cognitive function: Neuroanatomical, clinical and neuroimaging evidence. Rev Neurol 2001;33:582-591.

54. Buckner RL. The cerebellum and cognitive function: 25 years of insight from anatomy and neuroimaging. Neuron 2013;80:807-815.
55. Borgwardt SJ, McGuire PK, Aston J, Gschwandtner U, Pflüger MO, Stieglitz RD, et al. Reductions in frontal, temporal and parietal volume associated with the onset of psychosis. Schizophr Res 2008;106:108-114.

56. Andreasen NC, Pierson R. The role of the cerebellum in schizophrenia. Biol Psychiatry 2008;64:81-88.

57. Bernard JA, Mittal VA. Cerebellar-motor dysfunction in schizophrenia and psychosis-risk: the importance of regional cerebellar analysis approaches. Front Psychiatry 2014;5:160.

58. Baldacara L, Borgio JG, Lacerda AL, Jackowski AP. Cerebellum and psychiatric disorders. Braz J Psychiatry 2008;30:281-289.

59. Ben-Yehudah G, Guediche S, Fiez JA. Cerebellar contributions to verbal working memory: beyond cognitive theory. Cerebellum 2007;6:193-201.

60. Picard H, Amado I, Mouchet-Mages S, Olie JP, Krebs MO. The role of the cerebellum in schizophrenia: an update of clinical, cognitive, and functional evidences. Schizophr Bull 2008;34:155-172.

61. Andreasen NC, Paradiso S, O'Leary DS. "Cognitive dysmetria" as an integrative theory of schizophrenia: a dysfunction in cortical-subcorticalcerebellar circuitry? Schizophr Bull 1998;24:203-218.

62. Barch DM. Cerebellar-thalamic connectivity in schizophrenia. Schizophr Bull 2014;40:1200-1203.

63. Cahn W, Rais M, Stigter F, Van Haren N, Caspers E, Pol HH, et al. Psychosis and brain volume changes during the first five years of schizophrenia. Eur Neuropsychopharmacol 2009;19:147-151.

64. del Re EC, Konishi J, Bouix S, Blokland GA, Mesholam-Gately RI, Goldstein J, et al. Enlarged lateral ventricles inversely correlate with reduced corpus callosum central volume in first episode schizophrenia: association with functional measures. Brain imaging Behav 2016;10:1264-1273.

65. Fannon D, Chitnis X, Doku V, Tennakoon L, ÓCeallaigh S, Soni W, et al. Features of structural brain abnormality detected in first-episode psychosis. Am J Psychiatry 2000;157:1829-1834.

66. van Haren NE, Pol HEH, Schnack HG, Cahn W, Brans R, Carati I, et al. Progressive brain volume loss in schizophrenia over the course of the illness: evidence of maturational abnormalities in early adulthood. Biol Psychiatry 2008;63:106-113.

67. Rosa PG, Schaufelberger MS, Uchida RR, Duran FL, Lappin JM, Menezes PR, et al. Lateral ventricle differences between first-episode schizophrenia and first-episode psychotic bipolar disorder: a population-based morphometric MRI study. World J Biol Psychiatry 2010;11:873-887.

68. Saijo T, Abe T, Someya Y, Sassa T, Sudo Y, Suhara T, et al. Ten year progressive ventricular enlargement in schizophrenia: an MRI morphometrical study. Psychiatry Clin Neurosci 2001;55:41-47.

69. Gaser C, Nenadic I, Buchsbaum BR, Hazlett EA, Buchsbaum MS. Ventricular enlargement in schizophrenia related to volume reduction of the thalamus, striatum, and superior temporal cortex. Am J Psychiatry 2004; 161:154-156.

70. DeLisi LE, Sakuma M, Maurizio AM, Relja M, Hoff AL. Cerebral ventricular change over the first 10 years after the onset of schizophrenia. Psychiatry Res 2004;130:57-70.

71. Chung Y, Haut KM, He G, van Erp TG, McEwen S, Addington J, et al. Ventricular enlargement and progressive reduction of cortical gray matter are linked in prodromal youth who develop psychosis. Schizophr Res 2017;189:169-174. 